\title{
Low Expression of Human Histocompatibility Leukocyte Antigen-DR Is Associated with Hypermethylation of Human Histocompatibility Leukocyte Antigen-DR $\alpha$ Gene Regions in B Cells from Patients with Systemic Lupus Erythematosus
}

\author{
Hiroshi Sano, Laurel J. Compton, Naoko Shiomi, Alfred D. Steinberg, Richard A. Jackson, and Takeshi Sasaki \\ Koriyama Institute of Medical Immunology, Koriyama, Japan 963; Dana-Farber Cancer Institute, Boston, Massachusetts 02115; \\ National Institute of Arthritis, Diabetes, Digestive and Kidney Diseases, Bethesda, Maryland 20205; Joslin Diabetes Center, Boston, \\ Massachusetts 02115; and Tohoku University School of Medicine, Sendai, Japan 980
}

\begin{abstract}
The relationship between the expression of HLA-DR antigens and the HLA-DR $\alpha$ gene methylation was examined in systemic lupus erythematosus (SLE). Using permanent B cell lines, we found reduced DR expression in SLE. The low DR expression was correlated with high anti-DNA antibody titers in patients' sera. The amounts of DR $\alpha$ message were lower in SLE cells than in normal controls, suggesting that the low expression of DR antigens is associated with gene functions.

The extent of DNA methylation was examined at five CCGG sites in the HLA-DR $\alpha$ locus. DNA from both SLE and normal cells showed variable methylation patterns. Since the DR $\alpha$ gene is a single-copy gene, such a variability is the result of assaying a mixture of transformed clones containing methylated DR $\alpha$ gene, with other clones containing unmethylated $D R \alpha$ gene. A distinctive feature of normal cells was a consistent methylation pattern: 12 normal cell lines showed exactly the same pattern. In contrast, 28 SLE cell lines showed a cell-line-specific methylation, and hypermethylation at the DR $\alpha$ locus. The hypermethylation is often associated with transcriptionally inactive genes. Thus, our results suggest that $(a)$ B cells with hypermethylated DR genes might express no or few DR antigens; (b) the ratio of cells with differently methylated DR genes is consistent in normal individuals, while, in SLE patients, cells with hypermethylated DR genes predominate, resulting in apparently reduced DR antigen expression; and (c) the aberrant DR expression could be associated directly with immunoregulatory dysfunctions in SLE disease.
\end{abstract}

\section{Introduction}

Systemic lupus erythematosus (SLE) ${ }^{1}$ is a human autoimmune disease. Patients with SLE develop a variety of autoantibodies that react with autologous antigens including cellular, nuclear,

Address reprint requests to Dr. Sano, Biotechnology Institute, Ohgata, Akita, Japan 010-04.

Received for publication 16 February 1984 and in revised form 27 June 1985.

1. Abbreviations used in this paper: $\mathrm{C}$, cytosine; $\mathrm{CDNA}$, complementary DNA; EBV, Epstein-Barr virus; GC, glucocorticoids; kb, kilobases; $\mathrm{mC}$, 5-methylcytosine; mRNA, messenger RNA; SLE, systemic lupus erythematosus.

J. Clin. Invest.

(c) The American Society for Clinical Investigation, Inc.

0021-9738/85/10/1314/09 \$1.00

Volume 76, October 1985, 1314-1322 and cytoplasmic components (1-4). A genetic predisposition to the illness and numerous immune defects found in patients with SLE have suggested that the disease may result from abnormal gene expression in components of the immune system $(1,2,4)$.

The immune recognition and response are considered to be controlled by the major histocompatibility complex (MHC) or HLA in humans. The HLA complex contains two classes of cell surface antigens: class I and class II. The class II products are considered to play an important role in self-recognition, especially in the immune response by regulating the interaction between $\mathrm{T}$ cells and B cells (5). The class II antigens, or Ia antigens, contain at least three subsets; HLA-DR, DQ, and DP (5-7). Among them, HLA-DR molecules are dominant, composing up to $60 \%$ of total class II antigens at the membrane. The HLADR antigen consists of two different polypeptides: $\alpha$-chain and $\beta$-chain. The genes encoding these polypeptides have been isolated and sequenced (8-13). The genomic hybridization analysis indicated that the $\mathrm{DR} \alpha$ chain is encoded by a single-copy gene $(12,13)$.

There is strong evidence for the involvement of the HLA in diseases (14). Many of the HLA-DR-associated disorders are of the autoimmune type (15). Insulin-dependent juvenile diabetes is associated with DR3, myasthenia gravis with DR3, and rheumatoid arthritis with DR4. An increased frequency of DR3 has been reported in SLE patients $(6,15)$. It has been suggested that a particular HLA haplotype makes the individual either susceptible or resistant to certain diseases (15). However, few surveys have studied the relationship between disease activity and the cellular expression of HLA molecules.

Vertebrate DNA contains 5-methylcytosine $(\mathrm{mC})$ as a minor component, which occurs at a frequency of $\sim 1 \%$ of the total bases (16). The $\mathrm{mC}$ locates primarily in the $\mathrm{CpG}$ dinucleotide in mammalian DNA (17). The methylation of cytosines is a post-replicative enzymatic reaction catalyzed by DNA methyltransferase (18). The physiological functions of DNA methylation have not necessarily been clear. Surveys on the relationship between gene expression and gene methylation have revealed that transcriptionally active genes are often hypomethylated (1921). It was found that the gene function is not correlated proportionally to the overall methylation level in a given genome. The methylation at particular sites in that gene is critical for its expression (22). In the $\beta$-globin gene, only a few CCGG sites at the $5^{\prime}$ extragenic region were demethylated when the gene was activated (23). In some cases, the methylation of only one $\mathrm{CpG}$ site was enough to silence the gene $(24,25)$. The methylation of hypoxanthine phosphoribosyltransferase locus was studied on both active and inactive states (26). The active HPRT allele was associated with a consensus pattern of DNA methylation: hypomethylation at the $5^{\prime}$ region, and hypermethylation at the 
$3^{\prime}$ region. The inactive allele showed nonuniformity and less extensive hypomethylation at the $5^{\prime}$ cluster. It was suggested that both the methylated and unmethylated sites were important determinants of gene activity (26).

In an attempt to understand SLE at the molecular level, we asked whether HLA-DR antigen is expressed normally in SLE and if the genes encoding HLA molecules are expressed normally in SLE. To answer these questions, we have performed the following experiments. First, we have established permanent B cell lines from SLE patients by Epstein-Barr virus (EBV) transformation. Second, using these materials, we have assayed the amounts of HLA-DR antigens on the cell surface. Third, we analyzed the methylation patterns of the HLA-DR $\alpha$ gene by using methylation-sensitive restriction endonucleases and a DR $\alpha$ complementary DNA (cDNA) probe. In this communication, we report that, in SLE, HLA-DR expression is reduced and that such reduction is correlated with reduced amounts of $D R \alpha$ mRNA and with hypermethylation of $\mathrm{DR} \alpha$ gene regions.

\section{Methods}

Cells. Blood samples were from SLE patients followed at the Arthritis Branch, National Institute of Arthritis, Diabetes, Digestive and Kidney Diseases, National Institutes of Health, Bethesda, MD. All patients fulfilled the American Rheumatism Association criteria for SLE. Normal blood samples were obtained either from National Institutes of Health or from the Blood Component Laboratory, Dana-Farber Cancer Institute, Boston, MA. Permanent B cell lines were established by transforming peripheral blood lymphocytes by EBV as described (27). Briefly, peripheral blood mononuclear cells were isolated by Ficoll-Hypaque (Pharmacia Fine Chemicals, Piscataway, NJ) density gradient centrifugation. Collected lymphocytes were cultured at a density of $2 \times 10^{6}$ cells $/ \mathrm{ml}$. To 9 $\mathrm{ml}$ cell suspension, $1 \mathrm{ml}$ culture supernatant containing EBV (B95-8) was added. After 4-8 wk, cells were subcultured, and used for further assay. Established transformed cells were designated as LC lines with appropriate numbers. Normal cell lines were marked with capital $\mathrm{N}$ after the number.

Determination of immunoglobulin phenotypes. Surface immunoglobulins (Ig) were determined by the conventional immunofluorescene method using fluorescein isothiocyanate-labeled anti-human $\gamma, \mu$, or $\delta$ (Dakopatts Lab, Uppsala, Sweden and Behringwerke, Marburg, West Germany), and by the indirect antiglobulin rosetting reaction (28). Quantitative radioimmunoassay for the total IgG and IgM secreted from cells was performed in microplates as followings. A 50- $\mu$ l sample was incubated with $50 \mu{ }^{125} \mathrm{I}$-labeled anti-human $\gamma$ rabbit Ig $\mathrm{F}\left(\mathrm{ab}^{\prime}\right)_{2}$ or with ${ }^{125}$ I-labeled anti-human $\mu$ rabbit Ig $\mathrm{F}\left(\mathrm{ab}^{\prime}\right)_{2}$ in the well that had been coated with $\operatorname{IgG}(0.5 \mu \mathrm{g} / \mathrm{ml})$ or with $\operatorname{IgM}(0.5 \mu \mathrm{g} / \mathrm{ml})$ at $37^{\circ} \mathrm{C}$ for $90 \mathrm{~min}$. After washing with phosphate-buffered saline (PBS) three times, the radioactivity in each well was counted by a counter. For each radioimmunoassay, a fifteen-point standard calibration curve was prepared for IgG and IgM $(0.2 \mathrm{ng}-50 \mu \mathrm{g})$.

Flow cytometry analysis. An EPICS V flow cytometer (Coulter Electronics, Inc., Hialeah, FL) was used to measure cell surface antigens as described previously (29). The antibody binding reaction was performed as described previously (29). The murine monoclonal antibodies used were L243, P3, and 4F2. L243 reacts with nonpolymorphic regions of HLA-DR antigens (30); P3 is the myeloma antibody produced by the P3x63 cell line; 4F2 recognizes a 40,000-80,000 kD glycoprotein-activation antigen that is present on all tumor and EBV-transformed cell lines. P3 and 4F2 were used for negative and positive controls, respectively, together with L243 at each run. Depending upon setting and conditions of the machine, the distribution spectrum differed slightly at each run. To normalize the difference, one reference sample of the normal cells was included at each run.

Anti-DNA antibody assay. Total plasma $(\sim 20 \mathrm{ml})$ was used as the source of antibody. The proteins were precipitated repeatedly with $40 \%$ saturated ammonium sulfate as described (31). Immunoglobulin (Ig) was purified by affinity chromatography of Sepharose-bound anti-human IgA, IgG, and IgM (Miles Laboratories, Inc., Elkhart, IN) as described (32). Anti-DNA antibody activity was measured by the binding of ${ }^{32} \mathrm{P}$ labeled DNA. Calf thymus DNA was sheared by sonication and subjected to nick-translation with $\left[\alpha-{ }^{32} \mathrm{P}\right] \mathrm{dNTP}$ (Amersham Corp., Arlington Heights, IL) to give a specific activity of $\sim 10^{5} \mathrm{cpm} / \mu \mathrm{g}$. A $100-\mu \mathrm{l}$ reaction mixture contained $10 \mu \mathrm{g} \mathrm{Ig}$ and $1 \mu \mathrm{g}$ DNA $\left(10^{5} \mathrm{cpm}\right)$ in PBS, and incubated at $37^{\circ} \mathrm{C}$ for $30 \mathrm{~min}$. The reaction mixture was diluted twofold with cold PBS and applied onto a nitrocellulose paper that was treated previously with $0.5 \mathrm{M} \mathrm{KOH}$ as described (32). After being washed with cold PBS, the nitrocellulose paper was dried and counted for radioactivity. The antibody activity was scored on a $0-10$ scale, where 0 is no DNA binding and 10 is $100 \%$ binding of input DNA under the experimental conditions. At least three different tests, each with duplicated tubes, were done and average values were calculated.

DNA and RNA hybridization. DNA was extracted from B cell lines as described (33). DNA samples were digested with appropriate restriction endonucleases, subjected to agarose gel electrophoresis, and transferred to nitrocellulose paper as described (32). RNA was extracted from B cells and transferred to nitrocellulose paper after agarose gel electrophoresis as described (34). The cDNA probes were pp34RI-3 (generous gift from Professor S. Weissman, Yale University) for the HLA-DR $\alpha$ gene, and pHD84 (generous gift from Professor G. Attardi, California Institute of Technology) for the dihydrofolate reductase gene. The probe was nicktranslated and hybridized to sample DNAs as described (33).

Nearest neighbor analysis. The sample DNA was subjected to nicktranslation in the presence of $\left[\alpha-{ }^{32} \mathrm{P}\right] \mathrm{dGTP}$ (Amersham Corp.; specific activity, $800 \mathrm{Ci} / \mathrm{mmol}$ ) as described (35). The radioactively labeled DNA was purified with repeated precipitation with ethanol and Sephadex G50 filtration, and hydrolyzed to 3'dNMP with micrococcal nuclease and spleen phosphodiesterase as described (35). The $3^{\prime} \mathrm{dNMP}$ was separated with two-dimensional thin layer chromatography, and the ratio between $\mathrm{mC}$ and cytosine $(\mathrm{C})$ was esimated from the radioactivity in each nucleotide as described (35).

\section{Results}

Establishment and characterization of EBV-transformed cell lines. B cell lines were established by EBV-transformation of peripheral blood lymphocytes from both SLE patients and apparently healthy donors. The immunoglobulin phenotypes were examined on the cell lines derived from 13 SLE patients, 10 control donors, and 2 patients with type I diabetes (as the disease control). Results are shown in Table I. All cell lines showed heterogeneous immunoglobulin production, indicating that EBV-transformation led to polyclonal cell activation. In all cell lines examined, surface $\mu$ and $\delta$ were dominant. Some cells expressed $\gamma$ and $\alpha$. The immunoglobulin phenotype did not differ between SLE and control B cells. This indicates that B cell populations that were transformed by EBV are the same in SLE patients and controls. Thus, EBV-transformed cell lines provide a unique circumstance in which the biochemical aspects of SLE B cells can be compared with those of healthy controls.

Low expression of $D R$ antigens in $S L E$ cell lines. The expression of DR antigens was determined by monoclonal antiDR antibody binding to B cells derived from SLE patients and control donors. Fig. 1 shows the representative patterns of DR expression analyzed by flow cytometry. First, we analyzed 12 control cell lines, which showed similar distribution spectra with a single, symmetrical peak as represented by LC63N (Fig. 1). Then we analyzed 46 SLE cell lines. 25 lines showed no difference from the control lines (Fig. $1 A$ ). We refer to these cell lines as type II. 21 cell lines showed reduced DR expression. The representative patterns are shown in Fig. $1 B$ and $C$. The spectrum 
Table I. Immunoglobulin Phenotypes of Cell Lines

\begin{tabular}{|c|c|c|c|c|c|c|}
\hline \multirow[b]{2}{*}{ Cell line } & \multicolumn{4}{|c|}{ Isotypes of surface Ig } & \multicolumn{2}{|c|}{$\begin{array}{l}\text { Amounts of } \\
\text { secreted Ig }\end{array}$} \\
\hline & $\mu$ & $\dot{\gamma}$ & $\alpha$ & $\delta$ & IgG & IgM \\
\hline & $\%$ & $\%$ & $\%$ & $\%$ & $\mu g / m l$ & $\mu g / m l$ \\
\hline 1. $\mathrm{LCO1}$ & 35.9 & 7.8 & 1.1 & 56.7 & 0.043 & 9.202 \\
\hline 2. $\mathrm{LCO} 2$ & 20.3 & 5.9 & 0 & 53.3 & 0.039 & 19.557 \\
\hline 3. $\mathrm{LCO8}$ & 39.5 & 9.0 & 1.4 & 53.6 & 0.190 & 7.908 \\
\hline 4. LC40 & 14.9 & 8.1 & 4.7 & 44.1 & 0.377 & 3.828 \\
\hline 5. LC42 & 43.5 & 11.2 & 1.4 & 47.6 & 0.153 & 3.574 \\
\hline 6. $\mathrm{LC} 47$ & 51.7 & 6.1 & 33.1 & 29.2 & 0.141 & 8.467 \\
\hline 7. LC53 & 50.5 & 1.3 & 1.2 & 39.6 & 0.059 & 7.185 \\
\hline 8. LC65 & & & & & 0.336 & 9.278 \\
\hline 9. LC66 & 45.1 & 6.7 & 2.0 & 35.2 & 1.062 & 4.925 \\
\hline 10. LC77 & 48.0 & 11.4 & 4.1 & 51.2 & 0.171 & 4.107 \\
\hline 11. LC78 & 52.2 & 4.2 & 2.1 & 21.6 & 0.156 & 10.931 \\
\hline 12. N.S. & 55.2 & 5.9 & 0 & 49.4 & 1.09 & 39.519 \\
\hline 13. H.S. & 67.8 & 7.4 & 1.0 & 55.4 & 1.810 & 52.946 \\
\hline 14. LC15N & 54.1 & 4.0 & 2.6 & 36.5 & 0.052 & 10.204 \\
\hline 15. LC25N & 52.4 & 5.3 & 10.3 & 41.3 & 1.149 & 29.593 \\
\hline 16. LC48N & 40.8 & 12.5 & 2.1 & 36.0 & 0.090 & 18.579 \\
\hline 17. LC49N & 28.4 & 3.9 & 2.9 & 52.8 & 0.075 & 8.501 \\
\hline 18. LC50N & 32.8 & 4.1 & 33.1 & 41.6 & 0.334 & 5.751 \\
\hline 19. LCS1N & 27.4 & 21.9 & 3.3 & 48.9 & 0.124 & 6.751 \\
\hline 20. LC57N & 33.9 & 5.1 & 1.8 & 47.3 & 0.125 & 33.177 \\
\hline 21. LC58N & 47.2 & 11.1 & 23.4 & 46.0 & 0.609 & 17.612 \\
\hline 22. LC61N & 44.7 & 4.9 & 2.4 & 58.7 & 0.213 & 3.861 \\
\hline 23. $\mathrm{LC} 62 \mathrm{~N}$ & $54: 1$ & 7.1 & 0.4 & 54.9 & 0.522 & 8.401 \\
\hline 24. LC75DM & 53.6 & 10.2 & 4.3 & 53.0 & 0.265 & 28.055 \\
\hline 25. LC76DM & 45.7 & 8.8 & 3.6 & 45.6 & 0.654 & 16.561 \\
\hline
\end{tabular}

Cell lines 1 through 13 were from SLE patients, 14 through 23 were from healthy donors, and 24 and 25 were from diabetes patients.

for LC65 (SLE) is barely shifted relative to that of control cells $(63 \mathrm{~N})$. The main difference is that LC65 has fewer cells that bound to L243 antibody. The amount of L243 binding sites per cell appears to be the same as the control. The distribution spectrum of LC66 (SLE) is shifted relative to that of the control $(63 N)$. This could be the result of fewer L243 binding sites per cell as well as fewer positive B cells. We refer to these cell lines as type $I$.

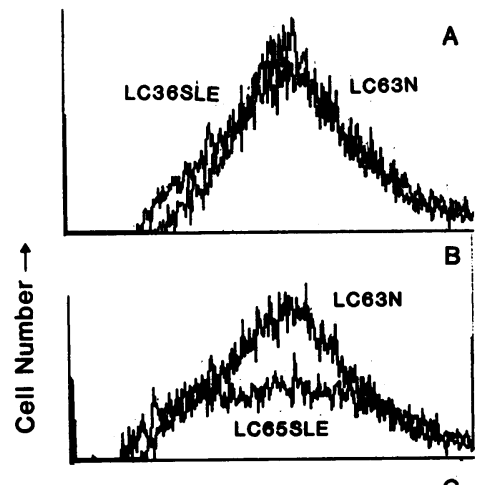

Figure 1: Comparison of the fluorescence profiles of B cells stained with $\mathrm{L} 243$ monoclonal anti-DR antibody. $(A)$ Comparison of LC63N (normal cell line) with LC36 (SLE cell line). This type was defined as type II. (B) Comparison of LC63N with LC65 (SLE cell line). (C) Comparison of LC63N with LC66 (SLE cell line). These cell lines expressing reduced antigens were defined as type $I$.
To examine the possibility that EBV-transformed B cells produced anti-DR antibody in vitro that blocked the assay system, we did the following experiments. Before staining cells with L243 monoclonal anti-DR antibody, we mixed the control cells with culture supernatant of SLE cells with low DR antigens (LC65). If the culture supernatant contained anti-DR antibody, the binding with L243 should be blocked. Results were negative (data not shown). It was concluded that the transformed B cells did not produce detectable anti-DR antibody in vitro. Another possible experimental barrier was considered: i.e., SLE cells produce normal amounts of DR antigens, but abnormally shed it. Shed DR antigens could compete with cells for L243 binding. Since before L 243 binding, cells were washed twice with plain PBS, shed, or secreted DR antigens in the culture medium should be absent in L243 binding system.

Correlation of DR expression with anti-DNA antibody quantity. To see if the reduced DR expression of B cells from SLE patients was associated with disease activity, we compared the DR-expression types with the quantity of anti-DNA antibody. After lymphocytes were isolated from patients' blood samples, immunoglobulin fractions were purified from the remaining plasma fraction, and were assayed for DNA binding activity. Fig. 2 shows the results. The relative activity of anti-DNA antibody was plotted in three groups; normal controls, type II (apparently normal DR expression), and type I (reduced DR expression). The distribution of antibody activity was heterogeneous, but the type I group appeared to contain the highest amounts of anti-DNA antibodies. The rank sum analysis indicated the $P$ value to be $<0.05$ between type I and type II $(P \leqslant 0.05)$.

Reduced amounts of $H L A-D R \alpha m R N A$. The level of $\mathrm{DR} \alpha$ mRNA was analyzed by Northern blotting. Representative results are shown in Fig. 3. The amounts of mRNA in three SLE cell lines were markedly reduced compared with that of control normal cells (LC63N). These cell lines showed reduced DR antigens as analyzed by flow cytometer (type I). Particularly, LC66 showed very low levels of the message, being consistent with results shown in Fig. 1. The data indicate that the low expression of DR antigens on SLE B cell surface is the result of reduced transcriptional activity of the DR genes.

Characterization of the $D R \alpha$ locus and probe. It has been found that the gene expression is often inversely correlated with DNA methylation. The transcriptionally active genes are less

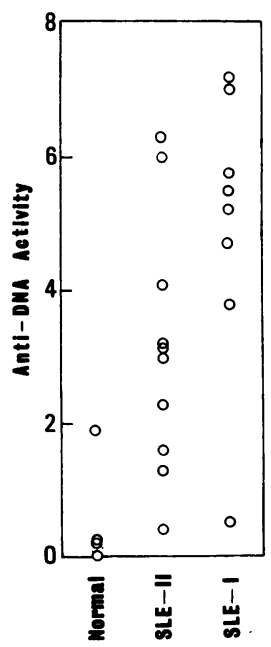

Figure 2. Relationship between DR expression and amounts of anti-DNA antibody. The DR expression was esimated by flow cytometer. The anti-DNA antibody titer was estimated on a $0-10$ scale, where 0 is no binding to DNA, and 10 is $100 \%$ binding of the input ${ }^{32} \mathrm{P}$-labeled DNA. SLE-I represents cells that express reduced amounts of DR antigens (type I), and SLE-II represents cells that express apparently normal amounts of DR antigens (type II). 


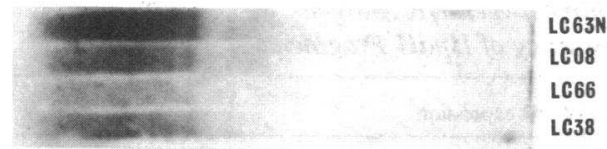

Figure 3. Expression of DR $\alpha$ mRNA in B cell lines. A 10- $\mu \mathrm{g}$ total cellular RNA was applied to a slot of $1.1 \%$ agarose gel and electrophoresed at $90 \mathrm{~V}$ for $6 \mathrm{~h}$. RNA was transferred to nitrocellulose paper and hybridized with the DR $\alpha$ probe, pp34RI-3. Samples were LC63N (normal cell line), LC08 (SLE), LC66 (SLE), and LC38 (SLE).

methylated than inactive genes. To see if the reduced DR expression in SLE patients is associated with DR gene methylation, we did Southern hybridization experiments using HLA$\mathrm{DR} \alpha \mathrm{cDNA}$ as the probe. The methylation was analyzed using two isoschizomers of restriction endonucleases, MspI and HpalI. The Hpall does not cleave the CCGG tetramer when the internal $\mathrm{C}$ is methylated, while MspI does. Fig. 4 summarizes the restriction map of the CCGG sequence in the vicinity of the probe of $3.4 \mathrm{~kb}$. The probe was constructed from an EcoRI-digested 3.4kb fragment, which contained exons 2, 3, 4, and 5 of the HLA$\mathrm{DR} \alpha$ gene (8). The MspI site was close to the EcoRI site, giving a 3.1-kb fragment. Consequently, MspI digestion generated almost exclusively a 3.1-kb fragment by hybridization, since the flanking fragments of $3.0 \mathrm{~kb}$ and $1.1 \mathrm{~kb}$ do not hybridize well with the probe.

Normal cell lines have a consistent methylation pattern at $D R \alpha$ locus. Nuclear DNA was isolated from established cell lines and the methylation at DR $\alpha$ locus was examined by HpalI/ MspI cleavage patterns. First, we examined the control B cells. As shown in Fig. 5, Mspl generated primarily a 3.1-kb fragment. Hpall generated 3.1, 4.2, 4.5, 6.1, 7.2, and 11-kb fragments, indicating that the methylations at these sites were variable within a cell line. Since the intensity of each band is almost equal, it seems that the ratio of DNA having $\mathrm{mC}$ at a given CCGG site to the total DNA is similar. Although it is difficult to estimate the exact ratio from the present data, $\sim 20-30 \%$ of the total DNA seems to contain $\mathrm{mC}$ at an arbitrary CCGG site. In other words, a large portion of DNA contains unmethylated cytosines at any CCGG site examined.

A characteristic feature of the $\mathrm{DR} \alpha$ locus was the uniformity of methylation in all cell lines derived from normal donors. We examined 12 control cell lines ( 7 samples are shown in Figs. 4 and 5), and found that all of them showed similar Hpall cleavage patterns, giving 3.1, 4.2, 4.5, 6.1, 7.2, and 11-kb fragments. Thus, normal cell lines contain the consensus methylation pattern at the DR $\alpha$ locus.

$S L E$ cell lines have variable methylation patterns at $D R \alpha$ locus. Figs. 6 and 7 show some representative cleavage patterns of DNAs from SLE B cells by HpaII and MspI. MspI generated a 3.1-kb fragment in all cells (LC38, LC39, LC65, and LC66),

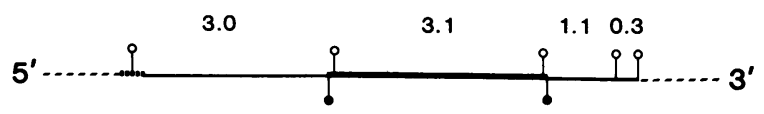

Figure 4. Tentative restriction map of HLA-DR $\alpha$ gene regions. The site for MspI (CCGG) is indicated with open circles, and the site for EcoRI is with closed circles. The thick line indicates the region of the probe cDNA; the broken line indicates the Alu sequence (8). Numbers indicate the distance between each Mspl site as expressed in kilobases $(\mathbf{k b})$.

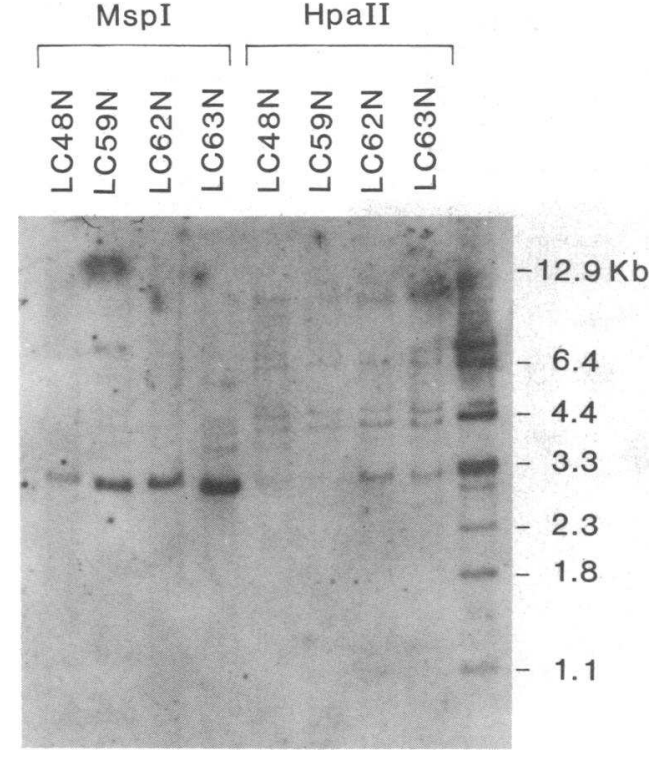

Figure 5. Southern hybridization analysis of DNAs from normal cell lines with HLA-DR $\alpha$ cDNA probe. Samples (10 $\mu \mathrm{g}$ each from LC48N, LC59N, LC62N, and LC63N) were digested with either MspI (30 U, New England Biolabs, Inc., Beverly, MA) or Hpall (30 U, New England Biolabs) for $16 \mathrm{~h}$ at $37^{\circ} \mathrm{C}$, and subjected to an electrophoresis on $0.8 \%$ agarose gel. The marker was constructed from various restriction fragments of pBR322 and pBR322-containing plasmids of known size.

indicating that the gene itself does not differ between control and SLE DNAs. On HpalI digestion, DNAs from four SLE cell lines were methylated to different degrees. LC38 lacked 3.1- and 4.2-kb fragments, showing that these sites are heavily methylated. LC39 lacked 4.2, 6.1, and 7.2-kb fragments. LC65 and LC66 showed a similar pattern with only $4.2 \mathrm{~kb}$ plus high molecular weight fragments. These cell lines were all of the type I group (see Fig. 1). Other examples are shown in Fig. 8. Each cell line

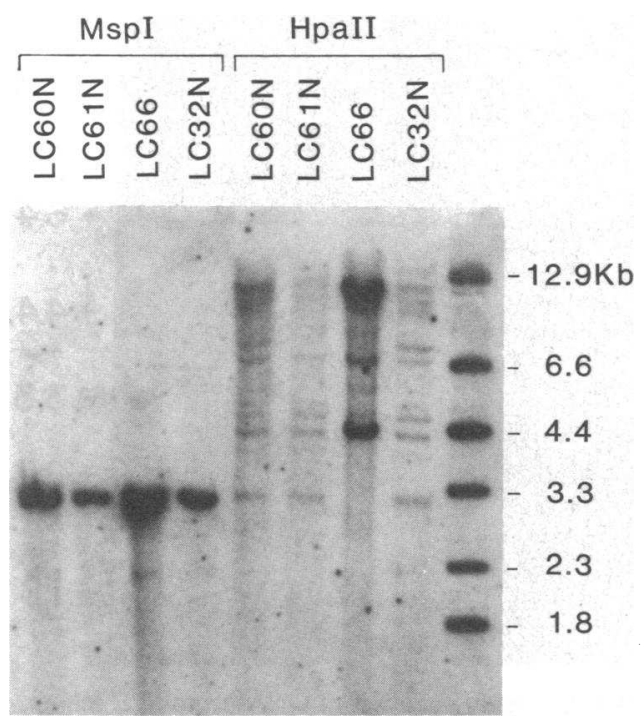

Figure 6. Southern hybridization analysis of DNAs from normal and SLE cell lines with HLA-DR $\alpha$ cDNA probe. Samples were LC32N (normal cell line), LC60N (normal cell line), LC61N (normal cell line), and LC66 (SLE cell line). Experimental procedures were the same as described in legend for Fig. 5. 


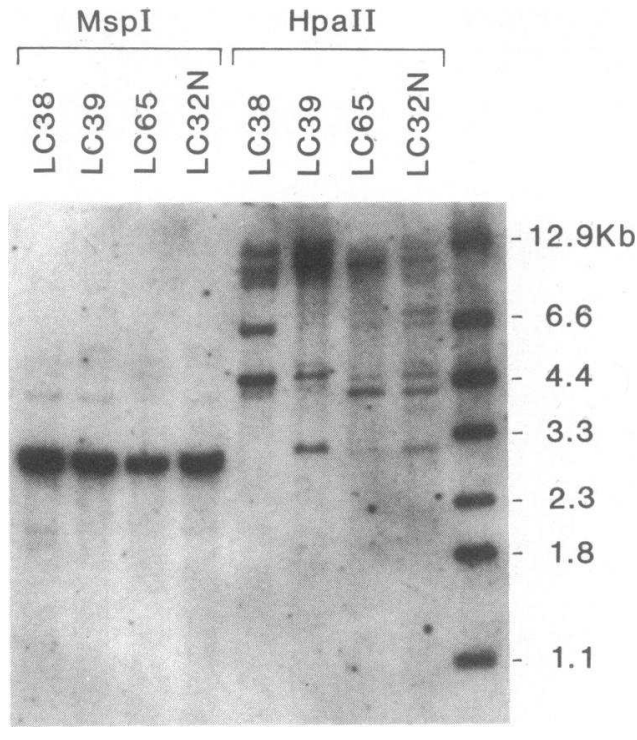

Figure 7. Southern hybridization analysis of DNAs from normal and SLE cell lines with HLA-DR $\alpha$ cDNA probe. Samples were LC32N (normal cell line), LC38 (SLE cell line, DR type I), LC39 (SLE cell line, DR type I), and LC65 (SLE cell line, DR type I, see Fig. $1 B$ ). Experimental procedures were the same as described in the legend for Fig. 5.

showed a unique methylation pattern. It is clear from these results that, in contrast to the normal cell lines, the methylation at the $\mathrm{DR} \alpha$ locus was cell line-specific in SLE B cells.

Hypermethylation at DRa locus in SLE B cells. Table II summarizes the extent of CCGG methylation in the $\mathrm{DR} \alpha$ locus

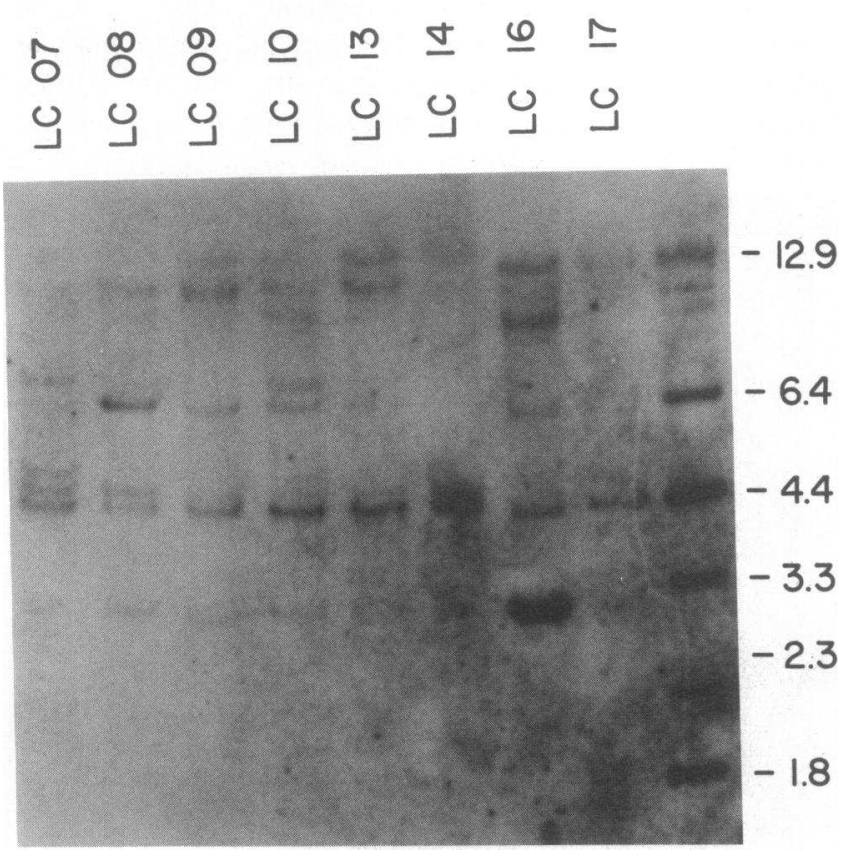

Figure 8. Southern hybridization analysis of DNAs from SLE cell lines with HLA-DR $\alpha$ cDNA probe. Samples were LC07 (DR type II), LC08 (DR type I), LC09 (DR type II), LC10 (DR type I), LC13 (DR type not measured), LC14 (DR type II), LC16 (DR type II), and LC17 (DR type II). Experimental procedures were the same as described in the legend for Fig. 5, except that samples were digested with HpaII only.
Table II. Relationship between DR Antigen Expression and Frequency of Hpall Fragments

\begin{tabular}{llll}
\hline & \multicolumn{2}{l}{ Type of DR expression } \\
\cline { 2 - 4 } $\begin{array}{l}\text { Hpall } \\
\text { fragment }\end{array}$ & SLE type I & SLE type II & $\begin{array}{l}\text { Normal } \\
\text { control }\end{array}$ \\
\hline$k b$ & & & \\
3.1 & $6 / 14(43)$ & $10 / 14(71)$ & $12 / 12(100)$ \\
4.2 & $9 / 14(64)$ & $13 / 14(93)$ & $12 / 12(100)$ \\
4.5 & $6 / 14(43)$ & $7 / 14(50)$ & $12 / 12(100)$ \\
6.1 & $9 / 14(64)$ & $9 / 14(64)$ & $12 / 12(100)$ \\
7.2 & $3 / 14(21)$ & $3 / 14(21)$ & $10 / 12(83)$ \\
\hline
\end{tabular}

Values are expressed as the numbers of cell lines that show the Hpall fragment in question over the total numbers of cell lines examined. In parentheses, the frequency is expressed in percent. SLE type I refers to cell lines with reduced DR antigen expression, and SLE type II refers to those with apparently normal expression of DR antigens.

of SLE and control cells. Cell lines are classified according to the DR expressing types. The appearance of HpaII fragments in each cell line was examined and its frequency was estimated. In DNA from type I cells, the $3.1-\mathrm{kb}$ fragment was observed in six cell lines out of 14 cell lines examined (43\%). In DNA from type II cells, the 3.1-kb fragment was seen in 10 lines out of 14 lines (71\%). In DNA from the controls, all cell lines showed the $3.1-\mathrm{kb}$ fragment $(100 \%)$. The frequencies of other fragments were similar to that of the 3.1-kb fragment. Thus, DNA from type I cells was methylated at elevated levels compared with that from control cells. The methylation extent of DNA from type II cells was between that of type $I$ and that of normal cell DNAs. These experiments show that certain regions in the HLA-DR $\alpha$ gene are hypermethylated in B cells from SLE patients.

Methylation of $\mathrm{Cp} G$ dinucleotide and of the dihydrofolate reductase gene locus. To see if the DNA hypermethylation is general in SLE cells, we examined the methylation of regions other than HLA-DR $\alpha$. Since most of DNA methylation in mammalian cells occurs at the $\mathrm{CpG}$ dinucleotide, we analyzed the methylation frequency of $\mathrm{CpG}$ in the total DNA from control and SLE cells. Results are shown in Table III. The ratio of $\mathrm{mCpG}$ to total CpG was $\sim 58 \%$ in all DNA examined regardless of the DR expressing types, indicating that the overall methylation in SLE cells does not differ from that in normal cells.

Figs. 9 and 10 show the methylation of the dihydrofolate reductase gene locus. To analyze the same Hpall fragments as used for HLA-DR $\alpha$ probe, the nitrocellulose paper used for

Table III. Frequency of 5-methylcytosine in $C p G$ dinucleotide

\begin{tabular}{ll}
\hline $\begin{array}{l}\text { Type of DR antigen } \\
\text { expression }\end{array}$ & Average $\mathrm{mCpG/total} \mathrm{CpG}$ \\
\hline & $\%$ \\
SLE type I & $57.8 \pm 7.5$ \\
SLE type II & $58.1 \pm 7.4$ \\
Normal control & $56.4 \pm 8.3$ \\
\hline
\end{tabular}

The average values were estimated from 8 samples of type I (reduced DR expression), 15 samples of type II (apparently normal DR expression), and 10 samples of normal controls. 


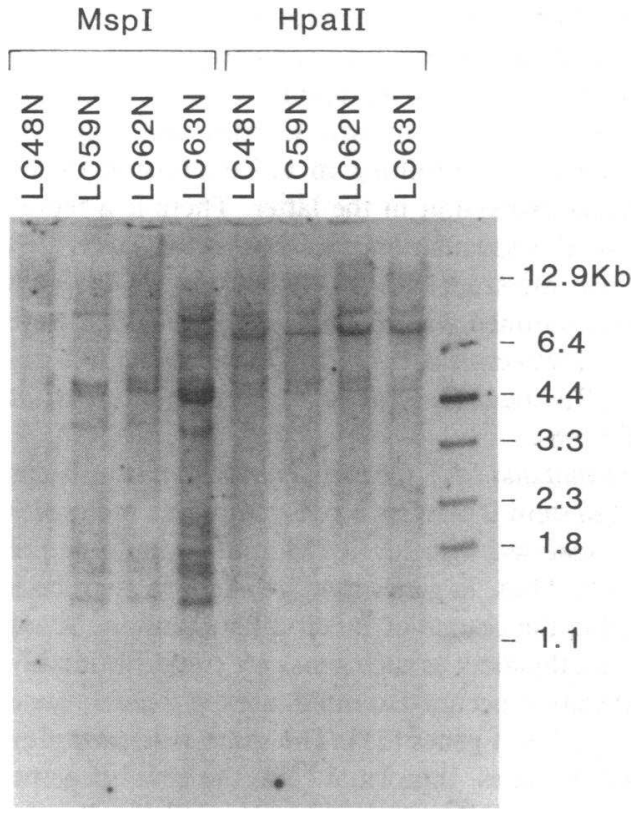

Figure 9. Southern hybridization analysis of DNAs from normal cell lines with dihydrofolate reductase cDNA probe. The nitrocellulose sheet shown in Fig. 5 was washed twice with $0.1 \mathrm{M} \mathrm{NaOH}$ in $2 \times$ SSC for $20 \mathrm{~min}$ at room temperature and rehybridized to pHD84 probe DNA.

HLA-DR $\alpha$ cDNA hybridization was washed with $\mathrm{NaOH}$, and rehybridized with the cDNA of dihydrofolate reductase. All cell lines, both SLE and normal, showed the same methylation pattern: no variation was observed. These results suggest that, in SLE cells, the aberrant methylation occurred at restricted regions in genomic DNA, including HLA-DR $\alpha$ locus.

\section{Discussion}

This paper describes the relationship between HLA-DR antigen expression and the methylation of HLA-DR $\alpha$ gene regions in B cells from SLE patients. Three experimental results are presented: B cell lines were established by EBV transformation, reduced DR antigens were observed in these cell lines, and reduced DR expression was correlated with reduced DR $\alpha$ message and with hypermethylation at the $\mathrm{DR} \alpha$ locus.

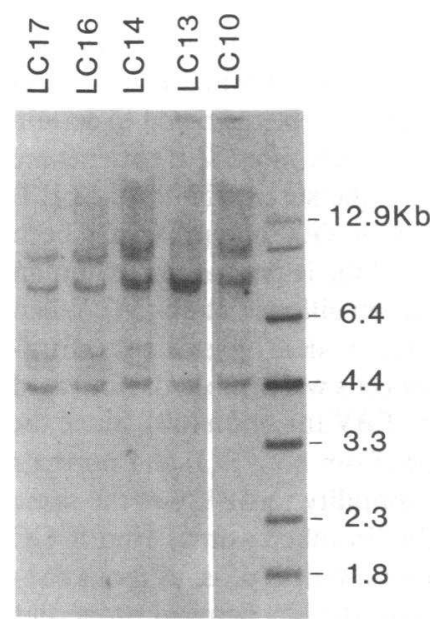

Figure 10. Southern hybridization analysis of DNAs from SLE cell lines with dihydrofolate reductase cDNA probe. Experimental procedures were the same as described in the legend for Fig. 9.
$E B V$-transformed cell lines as a material for biochemical studies. We have established more than $100 \mathrm{~B}$ cell lines from both SLE patients and healthy donors by EBV-transformation. The established cell lines were derived from peripheral blood lymphocytes, and could be a good source for biochemical studies, since they were available in considerable amounts at any time desired. Most B cell lines so far established were derived from peripheral blood mature lymphocytes, but recent studies have shown that EBV could transform pre-B cells originated from fetal livers $(36,37)$ and bone marrows $(37)$. Considering these observations, we asked two questions concerning the appropriate use of the established permanent B cell lines before further experiments: did EBV transform B cells equally between SLE and normals? And is it proper to analyze the surface antigens with EBV-transformed cell lines? The first question was answered by examining the immunoglobulin phenotypes. The expression of surface and secreted immunoglobulins was the same between SLE and controls, indicating that the B cells capable of EBV transformation do not differ between normals and SLE patients. The transformed cells were possibly derived from mature B cells in both healthy and SLE patients. This was important for experiments to be followed since DR antigens are expressed only in mature B cells, not in immature and pre-B cells (38). The second question was answered by several reports. The expression of various HLA antigens, including HLA-A, B, C, and DR, was successfully analyzed with EBV-transformed B cells (39). Therefore, we concluded that it was proper to analyze and compare the expression of DR antigens in EBV-transformed B cells between SLE patients and healthy donors.

Reduced DR expression in SLE. Among 46 B cell lines derived from SLE patients, about half showed reduced amounts of cell surface DR antigens. In addition, the amounts of DR antigens seemed to be correlated inversely with the amounts of anti-DNA antibody at the time of blood sampling. The decreased expression of HLA-DR antigens was also shown in peripheral blood monocytes from SLE patients (40). The involvement of DR antigens or Ia antigens in autoimmune diseases has been suggested (41-44). Self-antigens associated with self-Ia do not induce immune response through $\mathrm{T}$ cell reaction. When the selfIa molecule alters, the immune response occurs $(43,44)$. The alteration of Ia antigens, both qualitatively and quantitatively, may occur through chronic viral infection, drugs, mutation, and gene conversion $(41,42)$. The theory is partly supported by experiments showing that the recognition of foreign Ia antigens by $T$ cells led to an SLE-like disease in mouse $(43,44)$. Alternatively, abnormal la recognition may occur by $T$ cell defect, or miseducation of helper and/or suppressor $T$ cells (41). Whatever the mechanism is, the class II antigens play a key role in the immune regulation, and therefore, aberrant DR expression might be closely correlated with the immunoregulatory dysfunctions in SLE disease.

Two different mechanisms could result in reduced DR antigens. First, blockage of the surface antigens by autoantibodies causes an apparent reduction in DR molecules, and second, malfunctions of the DR producing system including the gene itself could account for the reduced amount of DR molecules. The first possibility is based on an observation that SLE patients produce anti-leukocyte antibodies $(45,46)$. Sera from SLE patients contain antibodies that block the binding of anti-Ia antibody to $T$ cells that express Ia antigens. It has been suggested that production of anti-Ia antibody in vivo by SLE patients led to reduced suppressor $T$ cell function (46). However, no evidence 
has been presented showing that SLE B cell functions are modified by autoantibodies blocking surface Ia antigens. Also, no anti-DR antibodies were detected in vitro under our experimental conditions, and the first possibility should be excluded. The second possibility should be considered by two different mechanisms: (a) SLE cells produced normal amounts of DR antigens, but their structure is altered, and L243 anti-DR antibody did not bind to them; and (b) SLE cells produced reduced amounts of DR antigens. The first assumption is probable, but we favor it less: the structural mutation, if any, should occur at the whole DR molecule, since L243 reacts at the nonpolymorphic regions of DR antigen, most likely at the $\alpha$-chain; no evidence has been presented showing the presence of "mutated DR antigens". The second assumption is more favorable for us, considering the reduced amounts of DR $\alpha$ message and the methylation patterns of $\mathrm{DR} \alpha$ gene regions as discussed below.

Association of hypermethylation with reduced $D R$ expression. We examined the extent of methylation at at least five CCGG sites in the HLA-DR $\alpha$ locus. In both normal and SLE cell lines, the methylation at a given CCGG site was variable within a cell line. Since the DR $\alpha$ gene is a single-copy gene, a CCGG site from a single clone should be either methylated or unmethylated. The variable methylation patterns observed in normal and SLE cells could result from studying mixed populations of cells, which might be a mixture of transformed clones in which the sites are methylated, with other clones, in which the sites are not methylated. Thus, established B cells are heterogeneous in terms of the DR $\alpha$ gene methylation.

A striking feature of the DR $\alpha$ gene from healthy individuals is a consistent pattern of methylation. B cell lines from 12 healthy persons showed exactly the same methylation pattern. This indicates that the ratio of cells with differently methylated DR genes is consistent, or well balanced in healthy persons. Striking features of the DR $\alpha$ locus from SLE patients are (a) the absence of consensus methylation pattern, and $(b)$ hypermethylation. B cell lines from 28 SLE patients showed a variety of methylation patterns, indicating that the ratio of cells with differently methylated DR genes is patient-specific. Since the extent of methylation in SLE was higher than that in controls, cells with hypermethylated DR $\alpha$ gene regions could predominate in SLE patients.

The DNA hypermethylation is often associated with transcriptionally inactive genes (19-21). Cells with unmethylated DR genes may express DR antigens, and cells with methylated DR genes may express no or few DR antigens. The apparently low expression of DR antigens in SLE could be the result of predominance of cells with hypermethylated DR genes among total B lymphocytes. Note, however, that type II cells, which express apparently the same amounts of DR antigens as normal cells, also showed hypermethylation in HLA-DR $\alpha$ regions. The methylation extent of type II cells was between that of normal cells and that of type I cells, which express reduced amounts of DR antigens. The question why type II cells express DR antigens normally despite the apparent hypermethylation can be explained by a theory that, for the normal gene functions, methylation/demethylation is critical at the particular sites rather than at the whole genome (22-25). In mammalian DNA, the frequency of the CCGG tetramer, of which methylation was examined in the present study, is $\sim 5 \%$ of the total methylatable CpG dinucleotide (47). Since $60 \%$ of CpG was methylated in B cell lines, the methylation at CCGG represents only $8 \%$ of the total methylation. Thus, it is reasonable to speculate that the
$\mathrm{DR} \alpha$ gene contains some critical regions other than CCGG, and that their methylation might be associated with relatively high methylation levels of other sites, including CCGG. The critical sites might not be methylated in type II cells, and might be methylated in type I cells, resulting in full expression in the former and reduced expression in the latter. There is a report that might support this speculation. In DNA from $T$ cells that do not express DR $\alpha$ messenger RNA (mRNA), all CCGG sites in the $\mathrm{DR} \alpha$ locus examined were methylated. T cells that were infected with T cell leukemia virus (HTLV) expressed DR antigens, and the $\mathrm{DR} \alpha$ locus was found to be demethylated at some CCGG sites (48).

Relation to normal and SLE B cell differentiation. Ia antigens are not expressed in stem B cells: as B cells mature, Ia molecules are gradually co-expressed with surface immunoglobulin at the membrane $(38,49)$. Thus, Ia genes that are silent in stem cells are activated during the course of B cell differentiation. Silent genes are usually methylated: as such genes are transcriptionally activated, demethylation occurs. Examples are the $\beta$-globin gene (50) and immunoglobulin genes (51). The same sequence may occur with HLA-DR genes. In normal cells, the genes become demethylated to express DR antigens. In many SLE cells, the demethylation probably does not occur, leaving the DR genes transcriptionally silent even after B cells mature.

Peripheral blood B cells from SLE patients were found to have reduced responsiveness to $B$ cell mitogens compared with those from normal persons $(2,52)$. The low response was attributed to higher spontaneous B cell proliferation in SLE patients (2). Also, SLE patients showed the greater numbers of Igproducing cells $(2,4)$. It was concluded that SLE patients have larger amounts of activated $B$ cells in vivo than do normal persons $(2,52)$, i.e., SLE B cells could be more differentiated than normal cells in terms of antibody production. Nevertheless, we observed the reduced DR expression in SLE B cells, i.e., SLE B cells are less differentiated in terms of DR expression. These observations suggest that the abnormal B cell functions in SLE might occur through disturbance of a concerted regulation of genes involved in differentiation. Compared with normal cells, SLE cells might contain some genes that are suppressed and others that are activated. In lupus-prone mice, primary B cell abnormalities have been identified (53-57), and the involvement of inherent genetic factors was suggested in lupus disease (5557). We propose that one of factors that are involved in B cell gene regulation is DNA methylation, and that aberrant methylation/demethylation during differentiation results in dysfunctions in SLE B cells.

Finally, note that our results obtained with EBV-transformed cells might reflect the molecular aspects of limited B cell clones in vivo. First, the target of EBV seems to be restricted to certain populations of B cells. Particularly, since most SLE patients are treated with glucocorticoids (GC), the susceptibility of SLE B cells to EBV might be influenced by GC therapy. It has been reported that $\mathrm{GC}$ treatments lowered the Ig production in human lymphocytes (58) and promoted B cell differentiation (59). When peripheral B cells were fractionated by density gradient centrifugation, only high density resting cells were infected. Activated low density cells were resistant to EBV infection (60). Since the phenotype of established cell lines from both SLE and normals did not differ (Table I), the susceptibility to EBV was the same between SLE and normal B cells. In other words, even if GC treatment affected the population ratio of $B$ cells, as far as concerned with EBV-transformed cells, the biochemical properties 
should be comparable between SLE and normals in vitro. But we should keep in mind that GC might alter the ratio of B cell subsets in vivo. Second, GC treatment might influence the DR gene expression at the transcriptional and translational levels. Several lines of evidence have indicated that steroid treatment stabilized some mRNAs (61) and promoted and/or inhibited some mRNA productions (62). We cannot exclude a possibility that the same sequence might occur in HLA-DR $\alpha$ mRNA production, although no evidence has so far been presented to support this idea. Further experiments are necessary to clarify these problems.

\section{Acknowledgments}

This work was supported by grants from National Institutes of Health (AM31240) and from the Vehicle Racing Commemorative Foundation.

\section{References}

1. Glass, D., and P. Schur. 1977. Autoimmunity and systemic lupus erythematosus. In Autoimmunity. N. Talal, editor. Academic Press, Inc., New York. 532-568.

2. Decker, J. L., A. D. Steinberg, J. L. Reinertsen, P. H. Plotz, J. E. Balow, and J. H. Klippel. 1979. Systemic lupus erythematosus: evolving concepts. Ann. Intern. Med. 91:587-604.

3. Koffler, D., V. Agnello, R. Thoburn, and H. G. Kunkel. 1971. Systemic lupus erythematosus: prototype of immune complex nephritis in man. J. Exp. Med. 134:169-179.

4. Smith, H. R., and A. D. Steinberg. 1983. Autoimmunity-A perspective. Annu. Rev. Immunol. 1:175-210.

5. Benacerraf, B. 1981. Role of MHC gene products in immune regulation. Science (Wash. DC). 212:1229-1238.

6. Dausset, J. 1981. The major histocompatibility complex in man. Science (Wash. DC). 213:1469-1474.

7. Auffray, C., J. Kuo, R. DeMars, and J. L. Strominger. 1983. A minimum of four human class II $\alpha$-chain genes are encoded in the HLA region of chromosome 6. Nature (Lond.). 304:174-177.

8. Das, H. K., S. K. Lawrence, and S. Weissman. 1983. Structure and nucleotide sequence of the heavy chain of HLA-DR. Proc. Natl. Acad. Sci. USA. 80:3543-3547.

9. Long, E. O., C. T. Wake, J. Gorski, and B. Mach. 1983. Complete sequence of an HLA-DR $\beta$ chain deduced from a cDNA clone and identification of multiple non-allelic DR $\beta$ chain genes. $E M B O$ (Eur. Mol. Biol. Organ.) J. 2:389-394.

10. Korman, A. J., C. Auffray, A. Schamboeck, and J. L. Strominger. 1982. The amino acid sequence and gene organization of the heavy chain of the HLA-DR antigen: homology to immunoglobulins. Proc. Natl. Acad. Sci. USA. 79:6013-6017.

11. Larhammer, D., L. Schenning, K. Gustafsson, K. Wiman, L. Cleasson, L. Rask, and P. A. Peterson. 1982. Complete amino sequence of an HLA-DR antigen-like $\beta$ chain as predicted from the nucleotide sequence: similarities with immunoglobulins and HLA-A, -B, and -C antigens. Proc. Natl. Acad. Sci. USA. 79:3687-3691.

12. Stetler, D., H. Das, J. H. Nunberg, R. Saiki, R. Sheng-Dong, K. B. Mullis, S. M. Weissman, and H. A. Erlich. 1982. Isolation of a cDNA clone for the human HLA-DR antigen $\alpha$ chain by using a synthetic oligonucleotide as a hybridization probe. Proc. Natl. Acad. Sci. USA. 79:5966-5970.

13. Wake, C. T., E. O. Long, M. Strubin, N. Gross, R. Accolla, S. Carrel, and B. Mach. 1982. Isolation of cDNA clones encoding HLADR $\alpha$ chains. Proc. Natl. Acad. Sci. USA. 79:6979-6983.

14. Kostyu, D. D., and D. B. Amos. 1981. The histocompatibility complex: genetic polymorphism and disease susceptibility. In The Metabolic Basis of Inherited Disease. J. B. Stanbury, J. B. Wyngaarden, D. S. Fredrickson, J. L. Goldstein and M. S. Brown, editors. McGrawHill Book Co., New York. 77-95.

15. Tiwari, J. L., and P. I. Terasaki. 1981. HLA-DR and disease association. In The Lymphocyte. K. W. Sell and W. V. Miller, editors. Alan R. Liss, Inc., New York. 151-163.

16. Shapiro, H. S. 1976. Distribution of purines and pyrimidines in deoxyribonucleic acids. In Handbook of Biochemistry and Molecular Biology, Nucleic Acids-Vol. II. G. D. Fasman, editor. CRC Press, Inc., Boca Raton, FL. H-80.

17. Doskocil, J., and F. Sorm. 1962. Distribution of 5-methyl-cytosine in pyrimidine sequences of deoxyribonucleic acids. Biochim. Biophys. Acta. 55:953-959.

18. Adams, R. L. P., T. Davis, J. Fulton, D. Kirk, M. Qureshi, and R. H. Burdon. 1984. Eukaryotic DNA methylase: properties and action on native DNA and chromatin. Curr. Top. Microbiol. Immunol. 108: 143-156.

19. Razin, A., and A. D. Riggs. 1981. DNA methylation and gene function. Science (Wash. DC). 210:601-610.

20. Ehrlich, M., and R. Y.-H. Wang. 1981. 5-methylcytosine in eukaryotic DNA. Science (Wash. DC). 212:1350-1357.

21. Doerfler, W. 1983. DNA methylation and gene activity. Annu. Rev. Biochem. 52:93-124.

22. Bird, A. P. 1984. DNA methylation: how important in gene control? Nature (Lond.). 307:503-504.

23. Busslinger, M., J. Hurst, and R. A. Flavell. 1983. DNA methylation and the regulation of globin gene expression. Cell. 34:197-206.

24. Fradin, A., J. L. Manley, and C. L. Prives. 1982. Methylation of simian virus $40 \mathrm{HpaII}$ site affects late, but not early viral gene expression. Proc. Natl. Acad. Sci. USA. 79:5142-5146.

25. Langner, K. D., L. Vardimon, D. Renz, and W. Doerfler. 1984. DNA methylation of three 5'CCGG3' sites in the promoter and 5' region inactivate the E2a gene of adenovirus type 2. Proc. Natl. Acad. Sci. USA. 81:2950-2954.

26. Wolf, S. F., J. J. Douglas, E. D. Lunnen, T. Friedmann, and B. R. Migeon. 1984. Methylation of the hypoxanthine phosphoribosyltransferase locus on the human X chromosome: implications for Xchromosome inactivation. Proc. Natl. Acad. Sci. USA. 81:2806-2810.

27. Compton, L. J., A. D. Steinberg, and H. Sano. 1984. Nuclear DNA degradation in lymphocytes of patients with systemic lupus erythematosus. J. Immunol. 133:213-216.

28. Coombs, A., A. B. Wilson, O. Eremin, B. W. Gurner, D. G. Haegert, A. Lawson, S. Bright, and A. J. Munro. 1977. Comparison of the direct antiglobulin rosetting reaction with the mixed antiglobulin rosetting reaction for the detection of immunoglobulin on lymphocytes. J. Immunol. Methods. 18:45-54.

29. Jackson, R. A., M. A. Morris, B. F. Hayes, and G. S. Eisenbarth. 1982. Increased circulating Ia-antigen-bearing T cells in type I diabetes mellitus. N. Engl. J. Med. 306:785-788.

30. Lampson, L. A., and R. Levy. 1980. Two populations of Ia-like molecules on a human B cell line. J. Immunol. 125:293-299.

31. Sano, H., and C. Morimoto. 1981. Isolation of DNA from DNA/ anti-DNA antibody immune complexes in systemic lupus erythematosus. J. Immunol. 126:538-539.

32. Sano, H., H.-D. Royer, and R. Sager. 1980. Identification of 5methylcytosine in DNA fragments immobilized on nitrocellulose paper. Proc. Natl. Acad. Sci. USA. 77:3581-3585.

33. Sager, R., A. Anisowicz, and N. Howell. 1981. Genomic rearrangements in a mouse cell line containing integrated SV40 DNA. Cell. 23:41-50.

34. Thomas, P. 1980. Hybridization of denatured RNA and small DNA fragments transferred to nitrocellulose. Proc. Natl. Acad. Sci. USA. 77:5201-5205.

35. Sano, H., H. Noguchi, and R. Sager. 1983. Characterization of DNA methyltransferase from bovine thymus cells. Eur. J. Biochem. 135: 181-185.

36. Katamine, S., M. Otsu, K. Tada, S. Tsuchiya, T. Sato, N. Ishida, T. Honjo, and Y. Ono. 1984. Epstein-Barr virus transforms precursor B cells even before immunoglobulin gene rearrangements. Nature (Lond.). 309:369-372.

37. Hansson, M., K. Falk, and I. Ernberg. 1983. Epstein-Barr virus transformation of human pre-B cells. J. Exp. Med. 158:616-622. 
38. Frelinger, J. A. 1981. Tissue distribution and cellular expression of Ia antigens. In Ia Antigens. S. Forrone and C. S. David, editors. CRC Press, Inc., Boca Raton, FL. 38-54.

39. Smith, L. K., H. R. Petty, P. Parham, and H. M. McConnell. 1982. Cell surface properties of HLA antigens on Epstein-Barr virustransformed cell lines. Proc. Natl. Acad. Sci. USA. 79:600-612.

40. Shirakawa, F., U. Yamashita, and H. Suzuki. 1985. Decrease in HLA-DR-positive monocytes in patients with systemic lupus erythematosus (SLE). J. Immunol. 134:3560-3562.

41. Eisenberg, R. A., and P. L. Cohen. 1983. Class II major histocompatibility antigens and the etiology of systemic lupus erythematosus. Clin. Immunol. Immunopathol. 29:1-6.

42. Volk, H.-D., and R. V. Baehr. 1984. The basis of autoimmunity in MRL-lpr/lpr mice and man. Immunol. Today. 5:257-258.

43. Gleichman, E., E. H. van Elven, and J. P. W. van der Veen. 1982. A systemic lupus erythematosus (SLE)-like disease in mice induced by abnormal T-B-cell cooperation. Preferential formation of autoantibodies characteristic of SLE. Eur. J. Immunol. 12:152-157.

44. van Rappard-van der Veen, F. M., U. Kiesel, L. Poels, W. Schuler, C. J. M. Melief, J. Landegent, and E. Gleichman. 1984. Further evidence against random polyclonal formation in mice with lupus-like graft-vshost disease. J. Immunol. 132:1814-1819.

45. Winfield, J. B., R. J. Winchester, P. Wernet, S. M. Fu, and H. G. Kunkel. 1975. Nature of cold-reactive antibodies to lymphocyte surface determinants in systemic lupus erythematosus. Arthritis Rheum. 18:1-18.

46. Okudaira, K., R. P. Searles, J. L. Ceappens, J. S. Goodwin, and R. C. Williams. 1982. Anti-Ia reactivity in sera from patients with systemic lupus erythematosus. J. Clin. Invest. 69:17-24.

47. Bestor, T. H., S. B. Hellenwell, and V. M. Ingram. 1984. Differentiation of two mouse cell lines is associated with hypomethylation of their genomes. Mol. Cell. Biol. 4:1800-1806.

48. Reitz, M. S. Jr., D. L. Mann, M. Eiden, C. D. Trainer, and M. F. Clarke, DNA methylation and expression of HLA-DR $\alpha$. Mol. Cell. Biol. 4:890-897.

49. Wall, R., and M. Kuehl. 1983. Biosynthesis and regulation of immunoglobulins. Annu. Rev. Immunol. 1:393-422.

50. Mavilio, F., A. Giampaoli, A. Care, G. Migliaccio, M. Calandrini, G. Russo, G. L. Pagliardi, G. Mastroberardino, M. Marinucci, and C. Peschle. 1983. Molecular mechanism of human hemoglobin switching: selective undermethylation and expression of globin genes in embryonic, fetal, and adult erythroblasts. Proc. Natl. Acad. Sci. USA. 80:6907-6911.

51. Storb, U., and B. Arp. 1983. Methylation patterns of immunoglobulin genes in lymphoid cells: correlation of expression and differentiation with undermethylation. Proc. Natl. Acad. Sci. USA. 80:66426646.

52. Ginsberg, W. W., F. D. Finkelman, and P. E. Lipsky. 1979. Circulating and pokeweed mitogen induced immunoglobulin secreting cells in systemic lupus erythematosus. Clin. Exp. Immunol. 35:76-88.

53. Theofilopoulos, A. N., and F. J. Dixon. 1981. Etiopathogenesis of murine SLE. Immunol. Rev. 55:179-216.

54. Steinberg, A. D., D. P. Huston, J. D. Taurog, J. S. Cowdery, and S. S. Raveche. 1981. The cellular and genetic basis of murine lupus. Immunol. Rev. 55:121-154.

55. Prud'homme, G. J., R. S. Balderas, F. J. Dixon, and A. N. Thofilopoulos. 1983. B cell dependence on and response to accessory signals in murine lupus strains. J. Exp. Med. 157:1815-1827.

56. Prud'homme, G. J., C. L. Park, T. M. Fieser, R. Koffler, F. J. Dixon, and A. N. Theofilopoulos. 1983. Identification of a B cell differentiation factor(s) spontaneously produced by proliferating $\mathrm{T}$ cells in murine lupus strains of the lpr/lpr genotype. J. Exp. Med. 157:730-742.

57. Hang, L., J. H. Slack, C. Amundson, S. Izui, A. N. Theofilopoulos, and F. J. Dixon. 1983. Induction of murine autoimmune disease by chronic polyclonal B cell activation. J. Exp. Med. 157:874-883.

58. Butler, W. T., and R. D. Rossen. 1973. Effects of corticosteroids on immunity in man. I. Decreased serum IgG concentration caused by 3 or 5 days of high doses of methylprednisolone. J. Clin. Invest. 52: 2629-2640.

59. Cupps, T. R., L. C. Edgar, C. A. Thomas, and A. S. Fauci. 1984. Multiple mechanisms of cell immunoregulation in man after administration of in vivo corticosteroids. J. Immunol. 132:170-175.

60. Aman, P., B. Ehlin-Henriksson, and G. Klein. 1984. EpsteinBarr virus susceptibility of normal human B-lymphocyte populations. J. Exp. Med. 159:208-220.

61. Cox, R. F. 1977. Estrogen withdrawal in chick oviduct. Selective loss of high abundance classes of polyadenylated messenger RNA. Biochemistry (Wash. DC). 16:3433-3442.

62. Lin, S., and S. Ohno. 1982. The interaction of androgen receptor with poly(A)-containing RNA and polyribonucleotides. Eur. J. Biochem. 124:283-287. 